\title{
A ESCOLA DOS TUPINAMBÁ DE OLIVENÇA-BA: ALGUNS APONTAMENTOS
}

JOSÉ VALDIR JESUS DE SANTANA ${ }^{1}$

$U E S B$

CLARICE COHN ${ }^{2}$

UFSCar

RESUMO: Interessa-nos apresentar, neste artigo, os modos como os Tupinambá de OlivençaBA têm produzido suas escolas e, consequentemente, os sentidos que diferentes sujeitos tupinambá, incluindo professores, estudantes e lideranças, têm atribuído à educação escolar. $O$ artigo foi feito a partir de resultados da etnografia que culminou em nossa tese de doutorado em Antropologia Social, defendida no Programa de Pós-Graduação em Antropologia Social da Universidade Federal de São Carlos. Ademais, nosso objetivo é compreender como a escola tem produzido Tupinambá fortes na cultura, como costumam afirmar, ou dito de outra forma, como são construídas pessoas tupinambá a partir da escola e dos discursos relacionados ao estar na cultura, a partir das "condições de socialidade" às quais Viegas (2003 e 2007) já fez referência.

PALAVRAS-CHAVE: cultura e escola; formação de professores; parentesco; povo indígena tupinambá.

\section{The school of the Tupinambá from Olivença-BA: some remarks}

ABSTRACT: Our aim in this study is to present the ways by which the Tupinamba from Olivença-BA (Brazil) have produced their schools and, consequently, the meanings attributed to school education by different Tupinambá citizens, including teachers, students and leaders. This study was compiled from results of the ethnography which culminated in our doctoral dissertation in Social Anthropology, defended in the Graduate Program in Social Anthropology of the Federal University of São Carlos. In addition, our goal is to understand how the school has produced Tupinambá individuals who are strong in the culture, as they often affirm, in other

\footnotetext{
${ }^{1}$ Graduação em Pedagogia e mestrado em Educação e Contemporaneidade pela Universidade do Estado da Bahia; doutorado em Antropologia Social pela Universidade Federal de São Carlos; professor Adjunto da Universidade Estadual do Sudeste da Bahia, nos cursos de Pedagogia, Ciências Sociais e no Programa de Pós-Graduação em Relações Étnicas e Contemporaneidade; E-mail: santanavaldao@ yahoo.com.br .

${ }^{2}$ Docente no curso de Ciências Sociais da Universidade Federal de São Carlos e credenciada no Programa de Pós-Graduação em Antropologia Social desta mesma universidade. Coordena o Laboratório de Estudos e Pesquisas em Antropologia da Criança (LEPAC) e coordenou o Observatório da Educação Escolar Indígena da UFSCar (OEEI/UFSCar), pelo qual realizou e orientou diversas pesquisas e organizou eventos com o tema da educação indígena e da educação escolar indígena. Faz pesquisas com os Xikrin do Bacajá desde 1992, e atua como antropóloga e cidadã nas áreas de educação escolar indígena, crianças indígenas e direitos indígenas. E-mail: clacohn@gmail.com .
} 
José Valdir Jesus de Santana e Clarice Cohn - A escola dos tupinambá de Olivença-BA...

words, how Tupinambá people are produced by the school and by the discourses related to being in the culture, based on the "conditions of sociality" mentioned by Viegas (2003 and 2007).

KEYWORDS: culture and school; teacher training; relationship; Tupinambá indigenous people.

\section{Introdução}

Interessa-nos apresentar, neste artigo, os modos como os Tupinambá de Olivença-BA têm produzido suas escolas e, consequentemente, os sentidos que diferentes sujeitos Tupinambá, incluindo professores, estudantes e lideranças, têm atribuído à educação escolar. Ademais, nosso objetivo é compreender como a escola tem produzido Tupinambá fortes na cultura, como costumam afirmar, ou dito de outra forma, como são construídas pessoas tupinambá a partir da escola e dos discursos relacionados ao estar na cultura a partir das "condições de socialidade" às quais Viegas (2003 e 2007) já fez referência.

Nosso investimento será, portanto, refletir acerca das "condições de socialidade tupinambá" (VIEGAS, 2003 e 2007) a partir da escola, na medida em que, conforme Strathern (2006, p. 40), o "conceito de socialidade [é utilizado] para referir-se à criação e manutenção de relações". No caso tupinambá, a escola tem se tornando o lugar da cultura, e estar na cultura é tanto uma cultura com aspas (no sentido dado por Carneiro da Cunha, 2009), por ela ter como interlocutor as relações que os mantêm como indígenas, como também uma cultura sem aspas, porque as lógicas de operação desse processo de interlocução e definições de sua indianidade são construídas dentro de sua socialidade, como já apresentado por Mejía Lara (2012), em sua dissertação de mestrado.

Do mesmo modo, a cultura, no caso tupinambá, parece ser pensada como autopoiese, assim como o parentesco piro estudado por Peter Gow 
(1997). Nesses termos, os agenciamentos em torno da cultura não se limitam a seus usos políticos, a marcadores diacríticos, do tipo cultura com aspas, mesmo que isto também esteja em jogo. A cultura, ou seja, ambas as culturas que Carneiro da Cunha diferencia, a com aspas e a sem aspas, precisa ser produzida na relação com os parentes, o que implica certas proximidades, o estar junto, o compartilhamento de memórias e de afetos, e isso tem se dado na escola, em suas aulas de cultura e em outras atividades que a escola possibilita, como a visitação a parentes nas comunidades, aulas em locais de retomadas ${ }^{3}$, em casas de farinhas, em intercâmbios construídos com comunidades remanescentes de quilombos, etc.

McCallum (2002, p. 3), sugerindo que "investigar o conceito de socialidade é pensar a noção de pessoa", nos ajuda a pensar de que forma socialidades são produzidas na/pela escola e como esta atua na produção de um tipo de pessoa tupinambá forte na cultura. Nesse sentido, o que significa estar na cultura, produzir-se forte na cultura a partir da escola?

Peter Gow (1997), em sua análise sobre o sistema de parentesco dos Piro da Amazônia peruana afirma que o parentesco para este povo deve ser compreendido como um

sistema autopoiético, isto é, um sistema que gera suas próprias condições de existência [...][na medida em que o] parentesco é, acima de tudo, um sistema de subjetividade, pois as estruturas básicas da consciência humana envolvem necessariamente a consciência de um eu [self] em meio a outros (GOW, 1997, p. 39).

As análises de Gow sobre a produção do parentesco como sistema autopoiético e sobre a escola como idioma de parentesco interessa-nos na medida em que nos faz pensar sobre a socialidade produzida na e pela escola tupinambá, levando-nos a entender os mecanismos de produção

\footnotetext{
3 “Retomadas" consistem em processos de recuperação, pelos indígenas, de áreas por eles tradicionalmente ocupadas, no interior das fronteiras da Terra Indígena - TI, e que se encontravam em posse de não índios. São ações encabeçadas por um cacique, algumas de suas lideranças e famílias indígenas que ao identificarem uma área improdutiva ou abandonada dentro da TI investem na ocupação territorial da mesma (MEJÍA LARA, 2012; ALARCON, 2013a e 2013b; ROCHA, 2014; CARVALHO, 2009 e 2011).
} 
cultural, os significados de estar na cultura, a construção de Tupinambá forte na cultura, os processos de produção de memórias e afetos, os sentidos das tradições e a relação com o conhecimento e sua produção.

A etnografia, que resultou em nossa tese de doutorado (SANTANA, 2015), nos mostrou que a escola é mais um lugar onde o parentesco é produzido, uma vez que a "socialidade, entendida como experiência vivida" (VIEGAS, 2007, p. 54) é constituída através das relações intersubjetivas. É através dessas relações que os Tupinambá fazem o seu próprio sentido do mundo, a partir da experiência vivida, e nisso vão atribuindo sentido às coisas. É nesse processo que a escola ganha sentido e é produzida. Ademais, conforme Viegas,

O conceito de socialidade tem essa vantagem de não
abstrair a realidade humana, e ainda a de nos oferecer
um caminho de análise histórica, segundo o qual a vida
social ganha sentido no modo imediato como os seres se
tornam seres-no-mundo. A abordagem da socialidade a
partir deste laço entre fenomenologia e a antropologia
conduz-nos, então, a priorizar conceitos como o de
"experiência vivida", "intersubjetividade" e "micro-
história" (VIEGAS, 2007, p. 54-55).

A socialidade é aqui entendida como um tipo de experiência vivida na escola, e a escola como lugar que produz e atualiza o parentesco, como um espaço de parentes, produzido pela socialidade, através de "dinâmicas intersubjetivas" (MCCALLUM, 2011). No caso tupinambá, a escola se constitui como idioma de parentesco e de produção de pessoa na medida em que esta aproxima parentes, construindo relações e fortalecendo laços; ao aproximarem-se, compartilham histórias, memórias, afetos, tensões, conflitos e experiências. Ter e estar na cultura passa pela apreensão e pela tomada de uma consciência histórica a partir de laços com os antepassados que viveram no território, com os encantados e com uma experiência e vivência naqueles padrões que consideram propriamente indígenas, como também com os elementos que possuem (artefatos - pinturas, cocares, saiotes, colares - utilizados em momentos cerimoniais e sociopolíticos, mas não exclusivamente) e 
com o conhecimento que adquirem (histórias antigas, músicas, danças, pinturas), o que possibilita prestígio e redes de articulações (tanto interna quanto externa), como bem definiu Rocha (2014).

Segundo Toren (2010, p. 29) "a socialidade é central para um argumento que sustenta a intersubjetividade". Contudo,

É preciso insistir que não se deve confundir intersubjetividade com interação social. Do mesmo modo, o processo de compreender o mundo intersubjetivamente não deve ser confundido com construção social. Onde o aprendizado é entendido como um processo micro histórico, o mundo habitado - apesar de operar segundo sua própria dinâmica - não pode nunca ser entendido independentemente do sujeito cognoscente (TOREN, 2010, p. 31).

Toren defende que a intersubjetividade se funda na ideia de o ser humano existir enquanto ser-no-mundo, também defendida por Viegas (2007) e, portanto, "mediado por outros seres humanos particulares" (TOREN, 1993, p. 468). Nesse sentido, seu investimento está em tentar explicar a forma pela qual os significados culturais são incorporados e, nesses termos, o desenvolvimento cognitivo é compreendido como um processo ao mesmo tempo ativo e mediado pelos outros com quem se está em relação; ademais, para a autora, o conhecimento deve ser compreendido tanto em nível intelectual quanto emocional, o que produziria, segundo Viegas (2007, p. 61), o entendimento dos "significados culturais como dinâmicas de socialidade, e a socialidade como dinâmica histórica".

Nesse sentido, interessa-nos pensar como o estar na cultura e tornar-se forte na cultura vão sendo produzidos a partir da escola e das relações que esta possibilita e articula, tanto interna quanto externamente; ademais, inspirados pela etnografia de Peter Gow (1997, 2006 e 2010), sobre os Piro, e Viegas (2003 e 2007) para os Tupinambá, buscamos pensar a escola tupinambá em termos de "idioma de parentesco", na medida em que, através dela (mas não somente) produzse um tipo de pessoa forte na cultura como reiteram os Tupinambá. 
Tornar-se forte na cultura implica em compartilhar memórias, afetos, em estar juntos (VIEGAS, 2003 e 2007) em produzir cultura e, nesse sentido (e para que isso ocorra), a escola tem se tornado central, na medida em que esta intensifica e amplia relações, tanto internas quanto externas e, do mesmo modo, como dizem os Tupinambá, a escola tem sido, ademais, o lugar da cultura, processo que tem sido observado em outros contextos, como nos demonstra Weber em sua etnografia sobre os Huni Kuin. Nesses termos, diversos autores têm demonstrado, tem ocorrido processos de "indigenização da escola" (BAPTISTA DA SILVA, 2013, p. 228), pensados a partir da ideia desenvolvida por Sahlins, a de "indigenização da modernidade" (1997a, 1997b e 2004) ou formas/mecanismos de "domesticação da escola", como analisado por Chates (2011 e 2013) para a educação escolar entre os Kiriri, e Melo e Giraldin (2012) para os Akwe-Xerente. Defendemos, nesse trabalho, (discutido de forma mais intensa ao longo da tese) que para os Tupinambá escola é cultura e, nesse sentido, o que os Tupinambá fazem não se limita a processos de "domesticação" ou "indigenização" da escola ${ }^{4}$.

\section{A escola e a produção de professor indígena}

Outro aspecto importante é que a escola, além de possibilitar a construção de um tipo de pessoa forte na cultura é, também, como me disse certa vez a professora Nete, "um espaço de fortalecimento da identidade do que somos nós povos nativos Tupinambá"s. Ademais, a escola parece atuar no fortalecimento da identidade de professores ou na construção de um tipo de professor tupinambá (ao menos do ponto de vista ideal) em especial daqueles que

\footnotetext{
${ }^{4}$ A pesquisa que temos realizado junto aos Tupinambá, no sentido de compreender como estes produzem e se apropriam da instituição escolar, que resultou em nossa tese de doutorado, teve início em abril de 2011 e se estendeu, de forma sistemática a maio de 2012, com retorno a campo em 2013 e 2014, por períodos mais curtos. No entanto, continuamos, até o presente momento, desenvolvendo pesquisa junto a esse povo. ${ }^{5}$ Nesse artigo, expressões e termos que se apresentam em itálico, correspondem às perspectivas nativas. Nos casos em que não se relacionarem a estas perspectivas, explicitaremos no texto.
} 
Não têm o conhecimento do que é o diferenciado, do conhecimento do que vem a ser valores e nem todos têm conhecimento do que é ser cultura, porque uma coisa é você viver, é você saber porque você nasceu, se criou, você viveu, e outra coisa é aquilo que você sabe porque quando se tornou um adulto ou um professor, você foi pesquisar para poder aprender (Professora Nete).

Ser professor tupinambá passa por um tornar-se professor e isso implica, como para muitos estudantes e a própria Nete, no aprendizado da cultura, no convívio com parentes, na valorização da memória e da história e de valores considerados tupinambá. A fala de Nete nos remete a outro aspecto já ressaltado por Viegas (2007, p. 224) "de que a experiência pessoal direta é a fonte de conhecimento à qual se dá mais valor" e está relacionada à memória dos eventos passados. Além disso, "a relevância do conhecimento pela experiência pessoal direta e a valorização das relações interpessoais são dois aspectos da socialidade que devem ser vistos articuladamente" (VIEGAS, 2007, p. 225).

Acusações de que muitos professores não valorizam a cultura, de que não participam do Poranci e não incentivam os alunos a participarem estão sempre presentes, especialmente em falas públicas, nos encontros pedagógicos e nas reuniões realizados pelos caciques e lideranças. Presenciamos muitas dessas acusações, especialmente vindas de caciques e que se dirigiam a professores que, segundo estes, não estavam entendendo a principal função da escola indígena. Essas acusações, ademais, partiam de muitos estudantes em relação a alguns professores que, segundo estes, "pouco se importavam com a cultura indígena, com o movimento indígena, estando mais preocupados com o salário que recebem". De modo geral, essas acusações eram justificadas a partir de duas perspectivas: alguns professores não estavam preocupados com a cultura na escola porque não se envolviam no movimento indígena ou porque não tinham a "vivência da cultura", sobretudo os que tinham se afastado do território, da relação com os parentes e dos modos de vida considerados propriamente indígenas; para outros, essa não valorização 
José Valdir Jesus de Santana e Clarice Cohn - A escola dos tupinambá de Olivença-BA...

da cultura vinha ocorrendo na medida em que muitos professores estavam se tornando evangélicos e, consequentemente, deixando de praticar "as coisas da cultura", incluindo o Poranci, ritual tupinambá, mas também a pintura corporal, o que enfraquecia a escola e, consequentemente, o movimento indígena.

Se o que "fortalece a gente é a nossa cultura", como afirmam os Tupinambá, é preciso praticá-la, produzi-la e incentivá-la na escola e isso implica em tornar a escola e o movimento indígenas fortes e, em especial, estudantes e professores que dela participam. Como argumentamos em nossa tese, a escola participa na produção de um tipo de pessoa forte na cultura, e tornar-se forte passa pelo compartilhamento de memórias e afetos, pela luta que o coletivo empreende para a demarcação do território, pela prática do Poranci, pela relação com os encantados ${ }^{6}$, pela visitação aos parentes, pela vivência da cultura, como já afirmado. Se neste movimento são produzidos estudantes fortes na cultura, o mesmo precisa ocorrer com os professores. Nesses termos, a escola produz, ao mesmo tempo, um tipo de professor indígena para as políticas do Estado (e vice-versa) ao mesmo tempo em que produz um tipo de professor que é valorizado no contexto de cada povo. Nisso, a escola atua na produção de um tipo de professor indígena que pode ser mais forte ou menos forte na cultura, como parecem sugerir os Tupinambá. Se alguns, por não terem a vivência da cultura acabam por se tornar um tipo de problema para a escola, para a comunidade e para o movimento indígena, é certo também que, a partir do envolvimento e do aprendizado da cultura e na cultura, nesse processo de "tornar-se professor", novas relações vão sendo construídas (com o aprendizado da memória e da história, na participação ritual, na intensificação das relações com os parentes, por exemplo).

Em 2011, a Lei 12.046, de 4 de janeiro, cria a carreira de Professor

\footnotetext{
${ }^{6}$ Para uma compreensão acerca da relação que os Tupinambá estabelecem com os encantados vê Couto (2008) e Ubinger (2012).
} 
Indígena (o Decreto de $\mathrm{n}^{\circ} 8.471$, de 12 de março de 2003, cria a categoria de Escola Indígena, no âmbito do Sistema Estadual de Ensino do Estado da Bahia) no Grupo Ocupacional de Educação, do Quadro do Magistério Público do Estado da Bahia, tendo sido recebida com entusiasmo pelos professores indígenas deste estado, uma vez que, ao criar a referida categoria, sinalizava para a abertura de concurso público voltado, especificamente, para os professores indígenas deste estado.

Em 29 de novembro de 2013 a Secretaria de Educação do Estado da Bahia e a Secretaria de Administração do Estado da Bahia (edital SAEB/4/2013) abrem concurso para o Magistério Estadual Indígena. Os Tumbalalá, alegando não terem sido consultados pelo Estado para a abertura do referido concurso entram com ação, através do Ministério Público Federal, pedindo a suspensão da realização das provas que aconteceriam no dia 12 de janeiro de 2014. Diante da ação tumbalalá, as provas foram realizadas, somente, em março. Em abril, findado o processo seletivo, o estado convoca os aprovados no concurso.

Mesmo sendo considerado um ganho importante para os povos indígenas do estado da Bahia, este concurso provocou uma série de conflitos, tanto com a Secretaria de Educação do Estado quanto com a empresa (Consultoria em Projetos Educacionais e Concursos CONSULTEC) responsável pela realização das provas, acusada de ter elaborado questões de forma equivocada e que não diziam respeito às realidades indígenas. Muitos professores, sentindo-se prejudicados, incluindo os Tupinambá, entraram com ações contra esta empresa. No final do processo seletivo, poucos professores Tupinambá ${ }^{7}$ que já atuavam na escola, contratados via Regime Especial de Trabalho - REDA ou como Prestadores de Serviço Temporário - PST, obtiveram aprovação no concurso, e isso gerou uma série de tensões internas à comunidade.

Acompanhei alguns desses desdobramentos e tensões em dois

\footnotetext{
${ }^{7}$ Ao todo, no final do processo seletivo, foram aprovados 27 professores, sendo que a grande maioria ainda não atuava como professores da Escola Estadual Indígena Tupinambá de Olivença.
} 
José Valdir Jesus de Santana e Clarice Cohn - A escola dos tupinambá de Olivença-BA...

momentos em que estivemos em campo, em 2014, com os Tupinambá, em Olivença. O primeiro ocorreu entre fins de fevereiro, quando me desloquei para Olivença com Clarice Cohn e na segunda semana de março, especialmente durante a semana pedagógica, organizada no início do ano letivo, em que fui convidado a participar do encontro para ajudar na discussão do Projeto Político Pedagógico da Escola. O segundo momento deu-se em fins de setembro, quando fui à Olivença participar do Primeiro Jogos Indígenas Estudantis Tupinambá e da Caminhada em Memória aos Mártires do Massacre do Rio Cururupe ${ }^{8}$.

Em minha chegada a Olivença em fins de fevereiro, vi que alguns

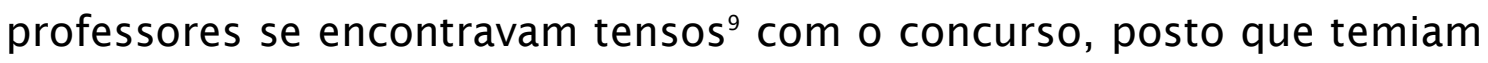
pela não aprovação, tendo em vista que, para os Tupinambá, o estado havia disponibilizado somente 40 vagas, insuficientes, naquele momento, para suprir as demandas da Escola. Em 2014, antes da realização do concurso, a Escola Estadual Indígena Tupinambá de Olivença (escola sede e núcleos) contava em seu quadro de funcionários com mais de 70 professores. Outro fator que causava temor entre os professores estava relacionado à inscrição no concurso de alguns Tupinambá que ainda não atuavam na escola indígena e que, potencialmente, poderiam tirar vagas daqueles que há um bom tempo já lecionavam nesta escola.

\footnotetext{
${ }^{8}$ A Caminhada em Memória aos Mártires do Massacre do Rio Cururupe é uma expressão pública do povo Tupinambá de Olivença, tendo surgido como meio de publicizar a historicidade e a presença indígena dos Tupinambá na região. A primeira Caminhada foi realizada em 2000, tendo a escola indígena como articuladora, juntamente com as comunidades e o Conselho de Caciques. Segundo Rocha (2014, p. 241), neste esforço de trazer à tona sua resistência histórica, há duas associações com fatos da história local que os indígenas explicitam: a primeira diz respeito à conhecida "Batalha dos Nadadores", enfrentamento ocorrido ainda no século XVI quando o governador Mem de Sá destruiu diversas aldeias no entorno da região de Ilhéus e terminou por matar centenas de indígenas em uma sangrenta batalha no rio Cururupe; e a segunda trata de recordar durante a Caminhada a figura do caboclo Marcelino, que incorpora um misto de herói que concentra em si todas as qualidades necessárias de um "guerreiro tupinambá" ou "grande líder".

${ }^{9}$ Tensão que já tinha presenciado em 2013, quando o estado da Bahia sinalizava a possibilidade do concurso ainda naquele ano. Fui, inclusive, sondado por alguns professores, com quem tinha mais amizade, para criar um grupo de estudo e ministrar aulas sobre conteúdos relacionados à legislação voltada para a educação escolar indígena, o que acabou não ocorrendo, na medida em que já me encontrava assumindo as funções de professor na Universidade Estadual do Sudoeste da Bahia, Campus de Itapetinga e, nesse período, já não mais residia em Olivença, mas em Vitória da Conquista-BA. Fiquei sabendo por José Carlos, amigo e professor indígena, que um grupo de professores tinha organizado sessões de estudo com Márcia, funcionária da FUNAI em Ilhéus, responsável por questões relacionadas à educação e que mantêm boas relações com os Tupinambá.
} 
Trazemos o caso do concurso público para pensarmos sobre o que já nos referimos acima: a escola e os coletivos indígenas produzem um tipo de professor indígena a partir de uma multiplicidade de fatores, diferentemente do modo como o estado pensa e produz a categoria professor indígena. O concurso, fruto da luta do movimento indígena, constituía-se, sem sombra de dúvidas, como um ganho importante para este movimento, mas era, ao mesmo tempo, motivo de sérias preocupações entre os Tupinambá e outros povos indígenas da Bahia, como pude presenciar em outros momentos, como por exemplo, na Reunião Ordinária do Território Etnoeducacional Yby Yara ${ }^{10}$, ocorrida entre os dias 19 e 21 de dezembro de 2011 , em Ilhéus, em que se encontravam representantes dos diferentes povos indígenas da Bahia.

Essas preocupações não eram justificadas pelo simples fato de que alguns professores veteranos poderiam perder seus empregos (mesmo que seja também verdade), mas, em grande medida, questionava-se o fato de que muitos dos inscritos para o concurso não tinham qualquer tipo de relação com o movimento indígena, nem tampouco conhecimento acerca da realidade das comunidades, da escola e da cultura indígena. Faltaria a muitos desses potenciais professores, ao menos era o que demonstravam os Tupinambá, a "vivência da cultura", o conhecimento da história tupinambá, inclusive em relação à construção da educação escolar na aldeia, além da pouca relação com o movimento e a causa indígena, colocando em xeque o projeto de educação e de escola que tem sido

\footnotetext{
${ }^{10}$ A Reunião Ordinária do Território Etnoeducacional Yby Yara, em Ilhéus, sob coordenação de Rosilene Tuxá, teve como temática central o "Atendimento à Educação escolar Indígena: avanços, desafios e perspectivas". Esta reunião teve com objetivo geral aprofundar a formulação da política pública de educação escolar indígena, com base nos Planos Nacional, Estadual e Municipais de Educação, visando atender a demanda de educação intercultural do Território Etnoeducacional Yby Yara e propor encaminhamentos para o período de 2012 e 2013, assim como elaborar o regimento interno e instauração da Comissão Executiva do Território Etnoeducacional Yby Yara, tendo como focos: a) fortalecer a agenda pública da política de educação escolar indígena, na perspectiva da interdisciplinaridade, interculturalidade, especificidade e institucionalização das ações em curso; b) socializar as iniciativas de educação escolar indígena intercultural, para favorecer uma educação de qualidade; c) estabelecer estratégias para o atendimento da educação escolar indígena nos programas e projetos da educação de forma a garantir a especificidade e a qualidade na educação escolar indígena; articular ações conjuntas para o Território Etnoeducacional Yby Yara.
} 
pensado e construído por este povo, com muitos esforços, tensões e contradições, desde a década de 1990"1.

No retorno à Olivença, em setembro, em conversas que tive com alguns professores, essas preocupações continuavam, inclusive entre os que tinham sido aprovados no concurso e que já lecionam há muitos anos na escola indígena. Preocupações que os Tupinambá já apresentavam, sobretudo em relação a professores que já lecionavam na escola, mas que tinham pouco envolvimento com o movimento indígena e com a cultura, como já foi dito.

Como ouvi certa vez de um cacique, "professores bem vistos são aqueles bem mais voltados para a cultura". É por isso que "é na escola que a gente constrói a nossa cultura", como afirmou a cacique Jamapoty, mesmo que em muitos casos essa cultura seja do tipo cultura com aspas, como já nos disse Carneiro da Cunha (2009). Nesses termos, se cabe à escola construir cultura, cabe a esta, também, produzir um tipo de professor que seja capaz de multiplicar esse efeito. O professor indígena que o estado normatiza e produz (mesmo sendo necessário) não é, em muitos dos casos, o tipo de professor que os Tupinambá desejam para suas escolas. A fala de dona Genilda, anciã Tupinambá, é extremamente reveladora,

Nós somos um povo diferente, nós temos a nossa cultura. O que é a nossa cultura? Nós temos o nosso viver que é diferente; você vê que somos pessoas que não gostam de conversa, nós gostamos de viver a vida tranquila, porque antigamente a gente vivia; a gente caçava, a gente pescava, a gente dançava, vivia uma vida tranquila, não existia essa situação que existe hoje; o que precisamos hoje? Existem os professores indígenas; esses professores estão tendo que formar aula, porque eles estão ensinando, mas tem que aprender também; agora, por que eles têm que aprender, me responda qualquer um de vocês? Porque tem que aprender com os mais velhos, porque são os mais velhos que vão dizer como eles viviam; precisa os

\footnotetext{
${ }^{11}$ Questões similares foram observadas entre os Tupi Guarani de São Paulo, por Mainardi (2010a, 2010b e 2015).
} 
professores saberem para eles passarem para os alunos deles, porque nós estamos buscando do princípio; a gente não tinha cama, colchão, antigamente, a casa da gente era de palha, na hora que chovia caía tudo dentro de casa. Existe a nossa cultura, existem as nossas crenças, que hoje muitos índios vão entrando na lei do crente e estão abandonando; aí vão se enfraquecendo também, nisso vão se enfraquecendo, porque a lei do crente é uma e a da gente é outra. Nós temos os nossos espíritos que precisam ajudar a gente; quando o índio passa para lei do crente ele vai esquecendo disso tudo, porque uma vez eu fui na lei do crente e o pastor me falou que eu tinha que esquecer isso tudo, de tudo que eu sabia tinha que esquecer; eu pensei, não vou me esquecer do que eu sei porque me serviu até aqui, então vai me servir até... Eu fiquei sendo crente, mas não deu certo: um dia eu estava na Igreja e meu filho foi visitar a Igreja, aí o pastor fechou a porta e a janela... Então é isso que eu converso no nosso movimento, que nós temos nossas rezas, nós temos nossos contatos com nossos antepassados, nós somos pessoas diferentes, então a escola precisa disso tudo; os professores antes de abrirem sua aula, eles têm primeiro de fazerem $o$ Poranci, tem que rezar, tem que pedir aos nossos antepassados que nos ajudem; na hora que a gente balança nosso maracá, nossos antepassados estão perto da gente; e ainda tem essa, temos que pedir com respeito porque se a gente não tiver respeitando, em nosso trabalho não vem ninguém, não; porque se nós somos cismados e os antepassados? Eles são mais cismados que a gente. A gente precisa muita coisa na escola indígena, porque eu falo assim, os professores indígenas precisam passar algumas coisas também: antigamente a gente comia em gamela, não tinha tempero e a gente era um povo sadio; usava muita giroba, o nosso peixe assado, cozido. Precisa que os professores saibam disso para poderem passar para os alunos. Tem muita coisa para esse movimento e para vocês, professores; precisam aprender com os mais velhos, porque vai chegar o tempo de nós morrermos e vocês não terem esse conhecimento. Porque tudo isso ajuda no território, esse movimento chegou até aqui por causa das histórias velhas. Quando a antropóloga (referindo-se a Susana Viegas) chegou aqui foi perguntando como era que a gente vivia e a gente foi contando; a gente foi para brejo botar tapaje e ela foi com a gente para ver como eram as coisas; ela perguntou como era quando morria um índio aqui, o que a gente fazia. Quando morria um índio tinha um buzo, hoje é celular, mas antigamente para fazer contato com 
outro quando morria um parente tinha um buzo (quebra um litro de vidro no fundo e aí toca; esse barulho vai longe), assim a gente sabia e já ia pra lá; chegava lá e rezava; quando era de madrugada, pelo canto do galo, estava na hora de rezar o Santo Ofício para depois sair com o caixão, que o pessoal levava nas costas até Olivença. Todo o povo daqui desse meio está enterrado ali em Olivença. Enterrava lá porque lá era o coração da aldeia (Entrevista, março de 2012).

Como diz dona Genilda, "o movimento chegou até aqui por causa das histórias velhas", o que implica em esforço constante para aprendêlas, tanto por parte dos professores quanto dos estudantes. Por isso há a valorização da memória, dos tempos dos antigos, do que é considerado tupinambá. Todavia, esse processo de aprendizado é e tem sido atravessado por tensões, posto que se corre o risco de não fazê-lo plenamente. Esse processo de aprendizado envolve humano e não humano, incluindo os encantados, mas também implica em desejo, vontade em querer aprendê-lo (tanto conhecimentos escolares como não escolares, por mais que em muitas situações essa distinção não seja possível). Outra tensão vivida pelos Tupinambá, nesse processo de aprendizado da cultura dos antigos, das histórias velhas, diz respeito à presença dos evangélicos, sobretudo de professores, que, segundo muitos, têm deixado de viver e praticar a cultura, inclusive na escola, especialmente por não participarem do Poranci (acusações que partem, sobretudo, das lideranças e caciques).

É certo que para muitos desses professores não há contradição em ser Tupinambá e ser evangélico, mesmo não participando do Poranci. Alguns que não participam não o fazem por considerá-lo algo diabólico, como sugerem seus pastores: não participam, em grande medida, por terem "virado crentes", o que implica em cumprir certa etiqueta religiosa, posto que são, em certo sentido, vigiados quanto a determinadas posturas que devem ter por estarem na "lei dos crentes". Outros não veem contradição em ser evangélico e participar do Poranci. Os que são acusados de não participarem deste ritual, criam suas justificativas, como 
ouvi certa vez de uma professora: "a cultura dos Tupinambá não se limita à religião". O certo é que existem distintas formas de ser Tupinambá e evangélico ${ }^{12}$.

\section{A escola e a "qualidade" da educação}

Poucas vezes presenciamos em campo, em especial nos encontros de jornada pedagógica, nas reuniões com os professores, nos encontros com os pais e nas reuniões realizadas para a elaboração do Projeto Político Pedagógico do Colégio Estadual Indígena Tupinambá de Olivença, discussões em torno da falta de qualidade da educação escolar entre os Tupinambá. Não estou afirmando que o debate em torno da qualidade da educação não se faça presente, principalmente entre os que estão mais diretamente envolvidos com a escola, incluindo alguns professores, estudantes, lideranças, caciques, anciãos. O que o campo nos revelou é que esta não era a questão central. Sempre foi mais recorrente, nestes diversos momentos e encontros em que se discutiam as questões relacionadas à escola e à comunidade, o debate em torno da cultura na escola.

O certo é que os Tupinambá elaboram "sentidos alargados" em relação ao que a escola precisa produzir junto a esse coletivo. Uma escola que, segundo estes, está para "fortalecer identidade, produzir guerreiro e possibilitar a tomada do território"; tendo por função, ademais, "valorizar a tradição, a cultura" e "fortalecer o movimento indígena". A escola é pensada para além da estrutura física e do ensinar "a ler e escrever" e se articula a diferentes demandas que dizem respeito à luta pelo território, ao fortalecimento e à produção da cultura, a afirmação da identidade e da diferença, à construção de sentidos para a tradição, para os saberes e conhecimentos tidos como tradicionais, que movimentam o desejo de estar na cultura e do tornar-se forte na cultura.

\footnotetext{
${ }^{12}$ Aspecto que vale a pena ser explorado em outro momento.
} 
Nesse sentido, a escola é muito mais que o lugar do aprendizado da leitura e da escrita (por mais que essa necessidade se coloque para os Tupinambá, a partir de diferentes perspectivas, em especial para muitos pais). Não é à toa que muitos que chegam à escola, incluindo pesquisadores e os próprios bolsistas do PIBID $^{13}$, em um primeiro momento, enxergam a escola como sendo de péssima qualidade porque ela não estaria dando conta do "aprendizado da leitura e da escrita" ou, em outros termos, não está se fazendo com "qualidade", impressão que tive assim que chego à escola, antes de compreender os "sentidos alargados" ao qual nos referimos.

A (in) compreensão do que é uma educação de qualidade em contexto indígena, tem sido tributária deste modo de perceber a escola e o seu currículo a partir de uma perspectiva meramente escolarizante: uma "boa escola" está para a leitura e para a escrita e sua qualidade é medida, quase sempre, em função disso. É como se existisse uma imutabilidade em termos de papel (função) que a escola tem que desempenhar, em todos os contextos, independente do coletivo que venha acionar esta instituição. Construímos uma teleologia escolar que parece tributária de um tipo de evolucionismo.

Os Maxakali, por exemplo, como demonstra Alvares (2004), burlam essa teleologia e alargam a função/sentido da escola, capturando-a a partir de sua cosmologia. As escolas indígenas têm alargado a compreensão do que é considerado currículo, conhecimento e, nesse sentido, tensionado o campo curricular ou as teorias do currículo em suas diferentes perspectivas.

Em conversas com alguns bolsistas do PIBID, estes se demonstravam apreensivos diante dos "problemas" enfrentados pela

\footnotetext{
${ }^{13}$ Geralmente às segundas e quartas-feiras estudantes do curso de História da Universidade Estadual de Santa Cruz - UESC iam à escola sede, em Sapucaeira, posto que desenvolviam atividades como bolsistas do Programa de Iniciação à Docência - PIBID ${ }^{13}$, sob coordenação do Dr. Carlos José, indígena Xukuru, professor desta mesma Universidade. Contudo, antes de Carlos José, o referido programa era coordenado pelo Dr. Robson Norberto Dantas, do Departamento de Filosofia e Ciências Humanas da UESC, do qual Carlos José faz parte.
} 
escola que, de forma geral, estavam relacionados "à falta de qualidade do ensino" que se traduziriam no baixo desempenho dos estudantes em relação à leitura e à escrita. Assim, a escola, mesmo tratando das questões relacionadas à cultura indígena, como observavam estes bolsistas, parecia estar sempre sob suspeita, posto que não produzia tão desejada "qualidade". É nesse sentido que atua a teleologia escolar, como já afirmado.

No entanto, para os Tupinambá, a escola sempre foi valorizada como sendo o local de produção e de vivência da cultura. Era comum, inclusive, ouvir de muitos Tupinambá, quando circulávamos pelas comunidades, a queixa de que nestas (comunidades) a "cultura estava se perdendo", sendo pouco praticada e que caberia à escola valorizá-la e praticá-la. As falas de caciques e lideranças sempre giravam em torno desta necessidade: "não deixar a cultura morrer na escola" porque "o diferencial da escola indígena é a vivência da cultura" ou dito de outra forma, é preciso "estar na cultura" e experimentá-la para tornar-se forte.

Ao comentar com Cleusa Pinto e Gicélia (diretora e vice-diretora, respectivamente, à época da pesquisa) se as discussões em torno da "qualidade da educação" não eram recorrentes entre os Tupinambá, elas me respondem: "de fato, esta não é a questão principal". Não obstante, conversas em torno da "qualidade da educação" sempre foram recorrentes entre Cleusa e Gicélia, que sempre viam as "dificuldades de aprendizagem" e as defasagens de leitura e escrita como um grande problema. Em muitas dessas conversas, Gicélia sempre reiterava a necessidade de se elaborar projetos voltados para a leitura e escrita como forma de amenizar tais dificuldades.

Recorri às atas elaboradas pela escola, em relação aos anos anteriores a minha chegada a campo, no sentido de verificar em que medida as questões em torno da qualidade da educação tinham se tornado foco de discussão entre professores, caciques, lideranças e pais. Nas atas que analisei, entre os anos de 2009 e 2011 (atas produzidas nos encontros pedagógicos, nas reuniões de caciques e lideranças, nas 
reuniões de pais e do Conselho da Escola) essas discussões praticamente não aparecem. Contudo, nessas mesmas atas, é recorrente o debate em torno da cultura na escola e da necessidade de sua valorização, tanto por parte dos alunos como dos professores.

Os Tupinambá não querem uma escola que se limite, apenas, a ensinar a ler e escrever e, dessa forma, o que é considerado uma "boa escola" (e uma boa escola é quase sempre pensada nesses termos) é uma dimensão valorizada, mas parece não ser a mais importante para os Tupinambá, posto que, segundo eles, "a escolaridade não está só no ler e escrever, está na nossa identidade, está no conhecimento dos nossos valores, está na nossa cultura", como ouvi certa vez de uma professora. Por isso que a escola é valorizada e "não ter aula", não "ter escola" é sempre um problema, sobretudo para os estudantes e suas famílias. As queixas que estes apresentavam iam sempre nessa direção e, por vezes, muitos estudantes abandonavam a escola ou pediam transferência. Não faziam isso porque consideravam a escola ruim ou de qualidade duvidosa (ao menos não eram esses os argumentos recorrentes), mas reclamavam da ausência dos professores, da interrupção das aulas devido a problemas no transporte escolar ou quando estas eram interrompidas durante os períodos mais chuvosos, que inviabilizavam o funcionamento da escola, já que o transporte não conseguia circular pelas comunidades.

O que queremos reiterar é o que constitui ameaça à escola ou o que é motivo de preocupação para os Tupinambá não é a suposta falta de qualidade do ensino oferecido, como muitos imaginam, inclusive os representantes da Secretaria de Educação, da Diretoria Regional de Ensino - Direc 6, à época localizada em Ilhéus, que não perdiam a oportunidade em lembrar que o "Índice de Desenvolvimento da Educação Básica - IDEB'14 da escola indígena é muito baixo", mas sim o não funcionamento desta, isso porque, como apresentamos, é na escola e através dela que os Tupinambá atualizam relações, parentesco, aprendizados, produzem

\footnotetext{
${ }^{14}$ Em 2011, o IDEB da Escola Estadual Indígena Tupinambá de Olivença era de 1,3.
} 
cultura, tornam-se fortes, constroem sentimento de pertença e de luta pela território. As palavras da professora Nete e de José (estudante do ensino médio) são reveladoras nesse sentido:

Muitos querem escola só para aprender a ler e a escrever. Nossa escolaridade não está só no ler e escrever, está na nossa identidade, está no conhecimento dos nossos valores, está na nossa cultura. Muitos não têm o conhecimento disso, não estão se reconhecendo como índio, como índia. Ainda temos muitos parentes que pensam que a escola foi feita para surgir emprego. Ele ainda não está se vendo como um índio; ele ainda não está tendo o conhecimento do que é uma educação diferenciada. Os jovens que vivem mais na zona urbana, muitos têm também esse pensamento, de que a escola serve só para ler e escrever, porque já passam a vivenciar uma outra cultura, já passam a ter conhecimento daquelas músicas, daquelas danças, daqueles negócios esquisitos, feios; aí só querem estar cantando aquelas músicas; a partir daí eles acham que a escola é só para ler e escrever e não tem neles mesmo a valorização do diferenciado que é muito importante para a vida deles (Nete - Entrevista realizada em novembro de 2011, na EEITO).

Eu comecei a estudar na escola indígena na quinta série; ia da Tucum para escola; o caminho é ruim, o transporte é péssimo; nós cansamos muito na viagem; a escola é muito boa, gosto de estudar lá; é uma escola que tem uma cultura diferente, língua diferente, tem o português, mas tem o tupi; tem nossa cultura que é ensinada; é muito bom estudar com índio, vou assumindo minha cultura, e aprendendo mais o que ainda não sei; os mais velhos tem muitos conhecimentos que ainda não sei; aí eles vão passando através de cantos, de palestras e nós jovens estamos sempre buscando mais conhecimento para podermos ficar mais interligados no processo de cultura, de retomada, o que é ser índio mesmo, de verdade, viver nossa própria cultura. Ser índio de verdade é assumir sua cultura, lutar por sua terra, se integrar no movimento. Os policiais são respeitados pela fala, nós índios, somos respeitados pelas nossas vestes, pela nossa pintura; um índio bem aculturado [no sentido de viver a cultura] é um índio mais forte, um índio que não assume sua cultura é fraco; o índio que é índio vivencia a sua própria cultura, não se exclui de sua cultura; é uma vergonha um índio não assumir a sua cultura. Eu queria que nossa escola crescesse mais, 
porque tem poucas salas, queria que tivesse uma sala de informática adequada com internet, um laboratório de ciências, uma quadra melhor (somos índios, mas podemos ser atletas; quem sabe um dia um Tupinambá não esteja jogando lá no Brasil, na seleção brasileira); isso é um sonho para o futuro. A qualidade do ensino é boa; eu comparei o meu caderno com o caderno do meu sobrinho que estuda na escola Jorge Calmon (em Olivença), tudo que estava passando em matemática lá estava passando aqui; é bom em termos de educação; mas é ruim nas vezes que falta a aula, muita aula, quando tem chuva; tem professor que falta também, e quando as aulas retornam já esquecemos quase tudo que ele passou na matéria; dificulta bastante, questão de prova, assunto, atrasa muito. Aí a gente fica um pouco perdido nesse meio (José - entrevista realizada em Olivença, em julho de 2011)

\section{Os caminhos para a Escola}

Após o reconhecimento oficial pela FUNAI em 2002 e diante do crescimento da demanda por escola, em 2003 foi criada a Escola Estadual Indígena Tupinambá de Olivença ${ }^{15}$ - EITO, no âmbito da Secretaria de Educação do Estado da Bahia, que a partir desse momento se responsabiliza pela educação escolar, contratando professores, além de comprometer-se em construir a escola, posto que até aquele momento as salas de aula funcionavam em espaços improvisados e precários. A escola é construída e inaugurada em 2006, com sede na Comunidade de Sapucaeira. Neste ano, segundo o Censo Escolar, atendia-se a 325 estudantes do pré-escolar, da $1^{\text {a }}$ à $4^{\text {a }}$ série e Educação de Jovens e Adultos (FERREIRA, 2011, 2013). Tive acesso ao número de estudantes, através do Sistema de Gestão Escolar - SGE - do Estado da Bahia, entre os anos de 2010 e $2014^{16}$. Conforme o SGE, em 2010 estudaram na escola Estadual Indígena Tupinambá de Olivença 951 estudantes; em 2011, 72;

\footnotetext{
${ }^{15}$ Em julho de 2014, torna-se Colégio Estadual Indígena Tupinambá de Olivença, através da Portaria $n^{\circ}$ 5.745/2014. O Núcleo de Acuípe de Baixo, em julho de 2014, é tornado colégio, desligando-se, portanto, da escola sede, e passa a se chamar Colégio Estadual Indígena Tupinambá de Acuípe de Baixo.

${ }^{16}$ Esses mesmos dados me foram passados pela diretora da escola, Cleusa Pinto, no momento em que eu realizava a pesquisa de doutorado.
} 
em 2012, 831; em 2013, 729; e em 2014, 974 estudantes.

Em 2009, por exemplo, existiam 20 salas nucleadas ${ }^{17}$, contrastando com 17 núcleos $^{18}$ em 2014. Novas retomadas implicam em construção de novos núcleos; da mesma forma, quando ocorrem reintegrações de posse em áreas de retomadas, núcleos são desativados. A diminuição dos núcleos em 2014 esteve relacionada aos conflitos que se acirraram no território em 2013, entre os indígenas e os grandes proprietários da região, fazendo com que famílias indígenas, diante do agravamento das tensões, se deslocassem para outras localidades (entre as quais, outras áreas de retomadas e Olivença), provocando a diminuição do número de alunos e, portanto, o fechamento de alguns núcleos, conforme nos relatou a diretora da escola, Cleusa Pinto.

Acordava 5h30 da manhã e juntamente com Gicélia, algumas vezes com Katu e José Carlos (professores da escola sede) ou com Erlon (vicediretor), subíamos para a praça central de Olivença, onde pegávamos o ônibus (em algumas situações, Toyota, especialmente nos dias mais chuvosos) que saía às $6 \mathrm{~h} 30$ em direção à escola em Sapucaeira, levando estudantes, professores e outros funcionários. Alguns ficavam ao longo do caminho para assumirem suas atividades nos núcleos; outros, que moravam território a dentro ou às margens da estrada iam se juntando aos demais, nas muitas paradas feitas pelo transporte escolar.

De Olivença à escola sede, localizada em Sapucaeira, demora-se de 30 a 40 minutos. O trajeto é feito com muita dificuldade, uma vez que a

\footnotetext{
${ }^{17}$ Núcleo de Olivença; Núcleo de Águas de Olivença; Núcleo de Tucum; Núcleo de Itapoã; Núcleo de Lagoa do Mabaço; Núcleo de Mamão; Núcleo de Acuípe de Baixo; Núcleo de Acuípe do Meio I; Núcleo de Acuípe do Meio II; Núcleo de Santana I; Núcleo de Santana II (Aldeia Abaeté); Núcleo de Sant'aninha I; Núcleo de Sant'aninha II; Núcleo de Serra do Serrote; Núcleo de Serra Negra; Núcleo de Serra das Trempes I; Núcleo de Serra das Trempes II; Núcleo de Retomada de Coqueiros; Núcleo de Acuípe de Cima; Núcleo de Jairí.

${ }^{18}$ Núcleo Katuana; Núcleo de Águas de Olivença; Núcleo do Tucum; Núcleo do Itapoã; Núcleo do Mamão; Núcleo do Acuípe de Baixo; Núcleo do Acuípe do Meio I; Núcleo do Acuípe do Meio II; Núcleo do Abaeté; Núcleo do Sant'aninha; Núcleo da Serra Negra; Núcleo da Serra das Trempes II; Núcleo do Acuípe de Cima; Núcleo da Taja Jairy; Núcleo do Gravatá; Núcleo do Maruim; Núcleo do Tamandaré. Destes, somente os núcleos de Serra das Trempes II, Maruim, Tamandaré, Abaeté, Acuípe do Meio I, Mamão e Katuana, funcionavam nos turnos matutino e vespertino; o Núcleo de Itapoã funcionava nos três turnos. Os demais, só funcionavam em um turno.
} 
estrada apresenta-se muito precária, o que é motivo, sobretudo na época das chuvas, para a interrupção das aulas na escola sede e nos núcleos, diante da impossibilidade de circulação do transporte escolar. Nos dias chuvosos, em muitas situações, mesmo diante da tentativa de se chegar à escola, tivemos que retornar à Olivença, tendo em vista o perigo que a estrada oferecia. Em muitos dos trechos ou nos ramais que ligam as diferentes comunidades, de onde saem muitos estudantes para chegarem à escola em Sapucaeira ou em outros núcleos, só é possível circular com Toyota, que é o transporte mais utilizado pelos estudantes. Quase sempre essas Toyotas circulam lotadas com crianças, jovens e adultos que, todos os dias, driblam essas dificuldades. Driblam com certo entusiasmo, mas também com cansaço, sono, uma vez que precisam acordar muito cedo, em especial os que estão em comunidades distantes da escola sede.

No ônibus, de Olivença a Sapucaeira, foi comum encontrar estudantes dormindo, sobretudo os mais novos. Os jovens, quase sempre, estão com os celulares ligados, ouvindo músicas de diferentes estilos, como arrocha, funk e rap. Outros entoam cantos do Poranci, muitas vezes direcionados por professores, quase sempre os de cultura. À tarde, no retorno da escola à Olivença, o que sempre me chamou a atenção fora o fato das crianças, elas mesmas, se organizarem, no fundo no ônibus, para cantarem, na maior parte das vezes, cantos entoados durante o Poranci. As crianças costumam se divertir neste trajeto, mesmo diante das dificuldades enfrentadas pela péssima qualidade da estrada. Costumam ficar em grupos ou sentadas ao lado de um adulto.

Muitas crianças e jovens, ao circularem nas Toyotas, vão tendo dimensão do território, das suas paisagens, das dificuldades enfrentadas pelas comunidades, dos perigos, mas também dos processos de resistência. A viagem para escola materializa muitas outras dificuldades enfrentadas no dia a dia. Todavia, estas mesmas viagens acionam outros aprendizados e ao exporem muitas destas dificuldades, produzem novos sentidos. Ir à escola é, em certo sentido, resistir, resistir na cultura e pela cultura, pelo coletivo e pelas demandas por território. Ademais, nas 
Toyotas se fazem amigos, é possível a paquera, o namoro e outras formas de sociabilidade. Segundo Weber,

\begin{abstract}
No caso kaxi, em uma sociedade onde a divisão do gênero é tão marcada e as casas costumam ser razoavelmente distantes umas das outras, a escola passou a funcionar como local privilegiado para $\mathrm{o}$ convívio. [...] A escola, hoje, é parte integrante do cotidiano da aldeia e sua frequência é percebida quase como obrigatória para as crianças e jovens. No entanto, a sua "função" de local propício para possíveis flertes permanece forte, o que se percebe no capricho com que as meninas já mocinhas (13 anos) se arrumam para ir às aulas (WEBER, 2004, p. 99).
\end{abstract}

Ouvi, certa vez, alguns estudantes dizerem que o melhor de ir para a escola é o trajeto que fazem nas Toyotas. É no transporte apertado, nos tombos, nas subidas e descidas (algumas muito perigosas) que os estudantes vão construindo relações de cuidado, de afeto, companheirismo. O transporte escolar parece sinalizar, ao mesmo tempo, essa condição guerreira dos estudantes Tupinambá que, desde muito jovens, enfrentam dificuldades para irem à escola. Ouvi de uma professora, nessas idas e vindas para Sapucaeira, que "é preciso ser muito guerreiro e gostar muito da escola para poder enfrentar essa estrada".

É comum o transporte quebrar, fazendo com que os estudantes tenham que percorrer a pé distâncias significativas para chegarem em suas casas ou para encontrarem um transporte que substitua o quebrado, sobretudo nos dias mais chuvosos. Não foram raras as vezes que ônibus e Toyotas tombaram, deslizaram nas subidas de ladeiras muito escorregadias, o que geralmente causava alvoroço e preocupação entre os adultos e risos entre os mais jovens.

Quando estávamos na escola em Sapucaeira e a chuva começava a "se preparar no céu", o término das aulas era antecipado para que os estudantes e professores pudessem retornar a suas casas, já que muitos vêm de comunidades distantes, incluindo Serra Negra, Serra das Trempes, Serra do Serrote, Acuípe, Santana, Santaninha, Olivença, Tucum, dentre 
José Valdir Jesus de Santana e Clarice Cohn - A escola dos tupinambá de Olivença-BA...

outras, algumas destas com estradas de circulação difícil e perigosa.

Nas visitas feitas aos núcleos, no período de matrícula ou em reuniões com os pais e professores, enfrentávamos muitas dessas dificuldades, com Toyota quebrada ou atolada, e nisso tínhamos que esperar durante horas um novo transporte ou andar por longas distâncias para encontrar algum tipo de ajuda. Circulando pelas comunidades, tive a dimensão do quão difícil era chegar à escola em Sapucaeira, mas também o quanto esse deslocamento potencializa aprendizados, afetos e cuidados que são centrais para a produção de um tipo de Tupinambá forte na cultura.

Estudar é como fazer retomada, em duplo sentido. É resistência, diante dos perigos, das dificuldades que se enfrenta para chegar à escola. Alguns desses perigos são muito reais, sobretudo quando se instaura tensões mais agudas com os fazendeiros, dentro do próprio território. Ir à escola, nessas circunstâncias, é sempre perigoso. Por outro lado, estudar é retomar, de forma sempre atualizada, através do que se aprende na e pela escola, a história dos antepassados, suas lutas, resistências; é produzir e estar na cultura, como temos afirmado.

\section{Considerações finais}

Da mesma forma que "não é possível escola sem o território demarcado", como afirmam, parece-nos que é impossível, atualmente, conceber este território sem escola, posto que tanto um quanto outro são produzidos e fortalecidos neste movimento. Entre os Tupinambá, fazer escola, fazer política, fazer retomada, produzir escolas em retomadas, estar na cultura $w$ produzir cultura atualizam e produzem, além de identidade, parentesco, aparentamento, formas de socialidades consideradas indígenas. Outro aspecto importante é que ao se expandir pelo território, através dos processos de nucleamento, a escola produz o mesmo efeito, de aproximação e de fortalecimento, da produção de parentesco e da cultura, na medida em que vai aproximando, 
intensificando relações, fortalecendo e produzindo cultura, retomando e produzindo parentes.

Vimos, ademais, que os Tupinambá afirmam insistentemente que a escola é o lugar onde se constrói cultura, o lugar da cultura, visto que nas comunidades, a cultura tem se perdido, enfraquecido. Como sugerem, na e pela escola são construídas pessoas fortes, guerreiras, fortalecidas pela história e memória das lutas que os antepassados empreenderam para se manterem e defenderem o território, mas também pelo movimento que aproxima parentes, indígenas e não indígenas que frequentam a escola em Sapucaeira e os núcleos, na medida em que " $a$ escola é um patrimônio onde se juntam todas as comunidades", como ouvimos de uma professora.

A escola impregna os Tupinambá de força, produz corpos aparentados e tem sido um dos vetores acionados na produção de pessoas sabidas, o que implica na valorização e vivência da cultura, da tradição, mas também na compreensão de que é preciso capturar a leitura e a escrita, na medida em que, como ouvi de um estudante, é preciso ter índio estudado para cuidar dos parentes. Tornar-se sabido, no sentido dado pelos Tupinambá, é condição para manejarem novas relações, tanto internas quanto externas, construírem novas parcerias com instituições e coletivos em benefício do próprio povo. É por isso que a escola vai se tornando a "base de tudo", ajudando "no resgate da aldeia".

Resgatar e retornar à aldeia, ao território, acaba por nos dizer muito acerca do que os Tupinambá definem como estar na cultura. Retornar, resgatar e retomar, inclusive para aqueles que conseguiram permanecer na Terra Indígena e para os que a ela retornam, é condição para restabelecer as condições, que estavam perdidas, para criar socialidade, para se viver na cultura e produzir cultura para si, na relação com os parentes, com os encantados, com espaços de memória. O retorno ao território é em duplo sentido: é no sentido do retorno, da ocupação e de sua defesa, especialmente, daqueles que foram forçados a sair do território, quando perderam suas terras, mas também no sentido de fazer 
o território retornar, pelas ações de cuidado, de recuperação de áreas degradadas, que reconectam humanos e não humanos.

A expressão "é no juízo da gente que a gente tem, porque viu o que se passou", ouvida de uma anciã, tem possibilitado, através da valorização das histórias e memórias que estes carregam que muitos Tupinambá acessem e atualizem sentidos para estar na cultura, que reverberam na produção de corpos fortalecidos de estudantes, professores, lideranças, caciques, etc., posto que esta (a cultura) precisa ser incorporada, colocada no corpo, a partir das histórias e da memória, da pintura, do ritual, da circulação e do aprendizado no território, do habitar em áreas de retomada. A escola tem construído esse movimento (que não é nunca homogêneo) e, ao mesmo tempo, é construtora de novas demandas, alianças, aproximações e afastamento, e novos sentidos. Segundo Carvalho (2007, p. 31) "a educação indígena não pode, absolutamente, ser dissociada da demarcação e integridade dos territórios, do atendimento à saúde, nutrição e preservação ambiental, mediante políticas e práticas continuadas, informadas e avaliadas pelos próprios índios".

A escola Tupinambá tem possibilitado a construção de relações mais simétricas com não indígenas e instituições que se tornam parceiras para os mais diversos fins, incluindo a ONG Thidewá, com projetos voltados para a construção de vídeos sobre as aldeias e livros sobre a história dos Tupinambá; a Universidade Estadual do Sudoeste da Bahia, com as ações que têm sido desenvolvidas pela professora Dr $^{\mathrm{a}}$ Consuelo Paiva, no ensino na língua Tupinambá; a Universidade Estadual de Santa Cruz, que tem organizado anualmente, em parceria com os Tupinambá, o Seminário Índio Caboclo Marcelino, que nos últimos anos tem sido coordenado pelo professor Dr. Carlos José, desta mesma universidade; a Universidade do Estado da Bahia e o Instituto Federal da Bahia, através da Licenciatura Intercultural Indígena, que tem constituído grupos de pesquisadores indígenas que realizam pesquisas sobre seu próprio povo; além da Funai e outas instituições. 
Ademais, a escola tem produzido uma nova geração de lideranças, especialmente de estudantes, que tem se "voltado para a cultura", como ouvimos de professores Tupinambá. Os Tupinambá resistem, os estudantes e professores resistem e produzem, na luta diária, inclusive para chegar à escola, sentidos sobre a luta, resistência indígena, sobre sua cultura e nisso constroem seus projetos de presente e futuro. Ademais, a escola, ao produzir novos postos de trabalho, possibilita que muitos Tupinambá permaneçam no território e, com isso, possam cuidar de seus parentes, de modo a conciliar e atualizar "formas tradicionais de cuidado", como já revelados por Viegas (2007), através da comensalidade, da convivialidade, da co-residência, da produção de afetos, de lugares e memórias, com os novos agenciamentos que a escola tem construído.

\section{Referências bibliográficas}

ALARCON, Daniela Fernandes. O retorno da terra: as retomadas na aldeia Tupinambá da Serra do Padeiro, sul da Bahia. 2013, 343 f. Dissertação (Mestrado em Estudos Comparados sobre a América) - Instituto de Ciências Sociais, Programa de PósGraduação em Estudos Comparados Sobre as Américas, Universidade de Brasília, Brasília, [2013a].

. "Construir uma outra aldeia": vínculos sociais e territoriais no processo de retomada, aldeia Tupinambá de Serra do Padeiro, Bahia. Espaço Ameríndio, Porto Alegre, v. 7, n. 2, p. 96-146, 2013b. Disponível em: http://seer.ufrgs.br/index.php/EspacoAmerindio/article/view/42883. Acesso em: 15 fev. 2014.

ALVARES, Myriam Martins. Kitoko Maxakali: a criança indígena e os processos de formação, aprendizagem e escolarização. Anthropológicas, Recife, v. 15, n. 1, p. 49-78, 2004.

Disponível

em: http://www.revista.ufpe.br/revistaanthropologicas/index.php/revista/article/view/30.

Acesso em: 12 jul. 2009.

BAPTISTA DA SILVA, Sergio. Cartografia sociocultural de espaços e práticas educativos ameríndios: refletindo sobre a indigenização da escola. Espaço Ameríndio, Porto Alegre, v. 7, n. 2, p. 96-146, 2013. Disponível em: http://seer.ufrgs.br/index.php/EspacoAmerindio/article/view/42883. Acesso em: 15 fev. 2014. 
José Valdir Jesus de Santana e Clarice Cohn - A escola dos tupinambá de Olivença-BA...

CARNEIRO DA CUNHA, Manuela. "Cultura" e cultura: conhecimentos tradicionais e direitos intelectuais. In: Naify, 2009. p. 331-373. . Cultura com aspas e outros ensaios. São Paulo: Cosac

CARVAlHO, Maria R. G. Os índios pedem passagem. Ciência e Cultura, São Paulo, v. 59, n. 2, p. 29- 31, 2007. Disponível em: http://cienciaecultura.bvs.br/scielo.php?pid=S000967252007000200014\&script=sci_arttext. Acesso em: 08 jun. 2011.

O Monte Pascoal, os índios Pataxó e a luta pelo reconhecimento étnico. Cadernos CRH, Salvador, v. 22, n. 57, p. 507-521, 2009. Disponível em: <http://www.scielo.br/scielo.php?pid=S0103 49792009000300006\&script=sci_abstract\&tlng=pt>. Acesso em: 05 fev. 2010.

Índios do sul e extremo sul baianos: reprodução demográfica e relações interétnicas. In: OLIVEIRA FILHO, João Pacheco de (Org.). A presença indígena no Nordeste: processos de territorialização, modos de reconhecimento e regimes de memória. Rio de Janeiro: Contra Capa, 2011. p. 35-55.

CHATES, T. J. A domesticação da escola realizada por indígenas: uma etnografia histórica sobre a educação e a escola Kiriri. 2011, 181 f. Dissertação (Mestrado em Antropologia) - Programa de Pós-Graduação em Antropologia, Universidade Federal da Bahia, Salvador, [2011].

A domesticação da escola na perspectiva Kiriri. In: CÉSAR, América Lúcia Silva; COSTA, Suzane Lima (Org.). Pesquisa e escola: experiências em educação indígena na Bahia. Salvador: Quarteto, 2013.

COUTO, Patrícia. Morada dos encantados: Identidade e religiosidade entre os Tupinambá da Serra do Padeiro - Buerarema, BA. 2008, 169 f. Dissertação (Mestrado em Ciências Sociais) - Programa de Pós-Graduação em Ciências Sociais, Universidade Federal da Bahia, Salvador, [2008].

FERREIRA, Sonja M. M. "A luta de um povo a partir da educação": Escola Estadual Indígena Tupinambá da Serra do Padeiro, 2011. 153 f. Dissertação (Mestrado em Educação) - Programa de Pós-Graduação em Educação, Universidade do Estado da Bahia, Salvador, 2011.

Escola Indígena Tupinambá da Serra do Padeiro. In: CÉSAR, América Lúcia Silva; COSTA, Suzane Lima (Orgs.). Pesquisa e escola: experiências em educação indígena na Bahia. Salvador: Quarteto, 2013.

GOW, Peter. O parentesco como consciência humana: o caso dos Piro. Mana, Rio de Janeiro, v. 3, n. 2, p. 39-65, 1997. Disponível em: http://www.scielo.br/scielo.php?script=sci_arttext\&pid=S0104-93131997000200002.

Acesso em: 12 out. 2009. 
. Da etnografia à história: "Introdução" e "Conclusão" de Of Mixed Blood: kinship and history in Peruvian Amazônia. Cadernos de Campo, Curitiba, v. 15, n. 14/15, p. 197-226, 2006. Disponível em: http://www.revistas.usp.br/cadernosdecampo/article/view/50107. Acesso em: 07 set. 2010.

¿Podia ler Sangama?: sistemas gráficos, linguaje y shamanismo entre los Piro (Perú Oriental). Revista da FAEEBA - Educação e Contemporaneidade, Salvador, v. 19, n. 33, 2010.

MAINARDI, Camila. Construindo proximidades e distanciamentos: etnografia Tupi Guarani da Terra Indígena Piaçaguera/SP, 2010. 98 f. Dissertação (Mestrado em Antropologia Social) - Programa de Pós-Graduação em Antropologia Social, Universidade Federal de São Carlos, São Carlos, [2010ª].

O papel da escola no resgate cultural dos Tupi Guarani da Terra Indígena Piaçaguera-SP. Revista Pós em Ciências Sociais, São Luís, v. 7, n. 14, p. 45- 58, 2010 b. Disponível em: http://www.periodicoseletronicos.ufma.br/index.php/rpcsoc/article/view/562. Acesso em: 15 ago. 2012.

Desfazer e refazer coletivos: o movimento Tupi Guarani. 2015. 200 f. Tese (Doutorado em Antropologia Social) - Programa de Pós-Graduação em Antropologia Social, Universidade de São Paulo, São Paulo, [2015].

MCCALlUM, Cecilia. O Conceito de Socialidade na Teoria Antropológica. Conferência para Concurso Professor Titular Departamento de Antropologia. Salvador: UFBA, 2002.

Anatomia funcional na perspectiva indígena: Adaptação ontológica ou mudança de paradigma? 35 ${ }^{\circ}$ Encontro Anual da Anpocs- Associação Nacional de PósGraduação e Pesquisa em Ciências Sociais - GT23- - Novos modelos comparativos: investigações sobre coletivos afro-indígenas, 24 a 28 de outubro de 2011.

MEJÍA LARA, Ernenek. "Estar na cultura": os Tupinambá de Olivença e o desafio de uma definição de indianidade no Sul da Bahia. 2012, 153 f. Dissertação (Mestrado em Antropologia Social) - Programa de Pós-Graduação em Antropologia Social, Universidade Estadual de Campinas, Campinas, [2012].

MELO, Valéria M. C. de; GIRALDIN, Odair. Os Akwe-Xerente e a busca pela domesticação da escola. Revista Tellus, Campo Grande, v. 12, n. 22, p. 177-199, 2012. Disponível em: http://www.tellus.ucdb.br/index.php/tellus/article/view/279. Acesso em: 03 abr. 2013.

ROCHA, Cinthia Creatini da. "Bora vê quem pode mais": uma etnografia sobre o fazer política entre os Tupinambá de Olivença (Ilhéus, Bahia). 2014. 303f. Tese (Doutorado em Antropologia Social) - Programa de Pós-Graduação em Antropologia Social, Universidade Federal de Santa Catarina, Santa Catarina, [2014]. 
José Valdir Jesus de Santana e Clarice Cohn - A escola dos tupinambá de Olivença-BA...

SAHLINS, Marshall. O "pessimismo sentimental" e a experiência etnográfica: por que a cultura não é um "objeto" em via de extinção (parte I). Mana, Rio de Janeiro, v. 3, n. 1, p. 41-73, 1997a. Disponível em: http://www.scielo.br/scielo.php?script=sci_arttext\&pid=S0104-93131997000100002. Acesso em: 08 jul. 2009.

O "pessimismo sentimental" e a experiência etnográfica: por que a cultura não é um "objeto" em via de extinção (parte II). Mana, Rio de Janeiro, v. 3, n. 2, p. 103-150, 1997a. Disponível em: http://www.scielo.br/pdf/mana/v3n2/2442.pdf. Acesso em: 08 jul. 2009.

Cultura na prática. Rio de Janeiro: UFRJ, 2004.

SANTANA, José Valdir Jesus. "A letra é a mesma, mas a cultura é diferente": a escola dos Tupinambá de Olivença. 2015. 241 f. Tese (Doutorado em Antropologia Social) Programa de Pós-Graduação em Antropologia Social, Universidade Federal de São Carlos, São Carlos, [2015].

STRATHERN, Marilyn. O gênero da dádiva: problemas com as mulheres e problemas com a sociedade Malanésia. Campinas: UNICAMP, 2006.

TOREN, Christina. Making history: the significance of childhood cognition for a comparative anthropology of mind. Man, v. 28, p. 461-78, 1993.

A matéria da imaginação: o que podemos aprender com as ideias das crianças fijianas sobre suas vidas como adultos. Horizontes Antropológicos, Porto Alegre, v. 16, n. $34, \quad$ p. $19-48, \quad 2010 . \quad$ Disponível em: http://www.scielo.br/scielo.php?script=sci_arttext\&pid=S0104-71832010000200002. Acesso em: 20 jun. 2012.

UBINGER, Helen Catalina. Os Tupinambá da Serra do Padeiro: r eligiosidade e territorialidade na luta pela terra indígena. 2012, 189f. Dissertação (Mestrado em Antropologia) - Programa de Pós-Graduação em Antropologia. Universidade Federal da Bahia, Salvador, [2012].

VIEGAS, Susana de Matos. Socialidades Tupi: identidade e experiência entre os índioscaboclos (Bahia/Brasil). 2003, 423 f. Tese (Doutorado em Antropologia) - Faculdade de Ciências e Tecnologia, Universidade de Coimbra, Coimbra/Portugal, [2003].

Terra Calada: os Tupinambá na Mata Atlântica do sul da Bahia. Rio de Janeiro: 7Letras, 2007.

WEBER, Ingrid. Escola Kaxi: História, cultura e aprendizado entre os Kaxinawá do rio Humaitá (Acre). 2004, 182 f. Dissertação (Mestrado em Antropologia Social) - Programa de Pós-Graduação em Antropologia Social - Museu Nacional - Universidade Federal do Rio de Janeiro, [2004]. 
José Valdir Jesus de Santana e Clarice Cohn - A escola dos tupinambá de Olivença-BA...

Recebido em: 06/07/2017 * Aprovado em: 20/11/2017 * Publicado em: 30/06/2018 